\section{JURNAL ABDIMAS

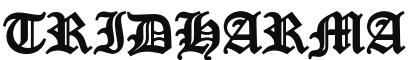

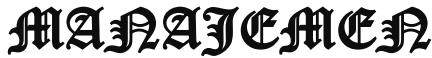

P-ISSN 2715-7105, E-ISSN 2716-070X

Jurnal ABDIMAS Vol. 1,No.2, Mei 2020, Hal (75-83)

@ Prodi Manajemen Fakultas Ekonomi Universitas Pamulang

Email: abdimasjurnal.unpam@gmail.com Telp: (021) 741-2566

\title{
MEMPERSIAPKAN GENERASI MUDA YANG KREATIF DAN INOVATIF DALAM MENGHADAPI INDUSTRI 4.0 DI RUMAH GEMILANG INDONESIA (RGI) DEPOK
}

\author{
Aceng Abdul Hamid, Ade Irawan, Laily Maknin Zubaedah, Nurselvy \\ Email : dosen00958@unpam.ac.id, 00651@unpam.ac.id, dosen01235@unpam.ac.id, \\ dosen02045@unpam.ac.id \\ DosenFakultas Teknik Universitas Pamulang
}

\begin{abstract}
ABSTRAK
Pengabdian ini berjudulmempersiapkan generasi muda yang kreatif dan inovatif dalam menghadapi industri 4.0 di Rumah Gemilang Indonesia (RGI) depok.

Tujuan pengabdian ini adalah untukMembantu memberikan arahan terhadap kepala keluarga, wanita ,dan anak-anak apa dampak dari kekerasan dalam rumah tangga dan Memberikan semangat dan motivasi bagi kepala keluarga,wanita dan anak anak dalam menjalani kehidupan yang lebih baik. Pengabdian Kepada Masyarakat (PKM) merupakan bagianTri Dharma Perguruan Tinggi yang melibatkan segenap sivitas akademik: dosen, mahasiswa, tenaga kependidikan serta alumni.Kegiatan Pengabdian Kepada Masyarakat di RGI Depok bertujuan untuk Menumbuhkan motivasi kreatifitas dan inovasi, mengasah kemampuan berwirausaha, Membudayakan semangat, sikap, perilaku dan kemampuan kreatifitas serta menumbuh kembangkan kesadaran dan orientasi wirausaha peserta didik di RGI Depok. Dalam pelaksanaannya kegiatan ini menggunakan metode ceramah, diskusi, presentasi serta game-game menarik yang berkaitan dengan materi diskusi. Setelah dilakukan kegiatan ini peserta didik RGI Depok dapat mengaplikasikan serta mengembangkan kreativitasnya untuk dapat bersaing saat ini.
\end{abstract}

\section{Kata Kunci :RGI Depok, Penyuluhan, Kreatif, Inovati}

\section{ABSTRAC}

This service is entitled to prepare young people who are creative and innovative in handling industry 4.0 at RumahGemilang Indonesia (RGI) Depok.

The purpose of this dedication is to help give direction to the head of the family, women and children what is the impact of domestic violence and provide encouragement and motivation for the head of the family, women and children in living a better life. Community Service (PKM) is part of the Tri Dharma of Higher Education which involves all academic community members: lecturers, students, education staff and alumni. Community Service Activities at RGI Depok aim to foster creativity and innovation, hone entrepreneurial skills, cultivate enthusiasm, attitudes, behavior and creative abilities as well as foster awareness and orientation of entrepreneurial students at RGI Depok. In the implementation of this activity using the method of lectures, discussions, presentations and interesting games related to the discussion material. After doing this activity RGI Depok students can apply and develop their creativity to be able to compete now.

Keywords:RGI Depok, Counseling, Creative, Innovative.

PENDAHULUAN

$\begin{array}{ccr}\text { Rumah } & \text { Gemilang } & \text { Indonesia } \\ \text { merupakan } & \text { sebuah unit } & \text { program }\end{array}$




\section{JURNAL ABDIMAS

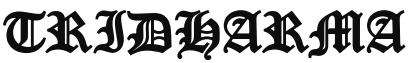

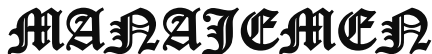

P-ISSN 2715-7105, E-ISSN 2716-070X

Jurnal ABDIMAS Vol. 1,No.2, Mei 2020, Hal (75-83)

@Prodi Manajemen Fakultas Ekonomi Universitas Pamulang

Email: abdimasjurnal.unpam@gmail.com Telp: (021) 741-2566 pemberdayaan dan pusat pelatihan (empowering and training center) di bawah direktorat Program Lembaga Amil Zakat Nasional Alazhar. Secara resmi, RGI mulai beroperasi sejak 1 Juni 2009 dengan melakukan sosialisasi kepada masyarakat. Sebagai bagian dari program pemberdayaan Lembaga Amil Zakat Nasional Alazhar, RGI mengadopsi model pesantren yang fokus pada penyelenggaraan pendidikan non formal dalam kemasan short course (kursus singkat).Perpaduan ini bertujuan agar para peserta pelatihan RGI tidak hanya menyerap pengetahuan dan keterampilan unggul yang menjadi pondasi masa depan mereka, tapi juga memiliki pengetahuan akidah islam yang baik.Peserta pelatihan di di Rumah Gemilang Indonesia (RGI) merupakan anak-anak yatim dan piatu maupunkaumduafa.Pesertadidikberasaldari berbagaidaerahdiseluruhndonesiamulaidari sabangsampaimerauke. Peserta didikakan di bina di RGI selama 6 bulanuntuksatuperiodebelajar.RumahGemi lang Indonesia Rumah Gemilang Indonesia saat ini membuka delapan jurusan, yaitu: Kelas Tata Busana, Kelas Fotografi dan Videografi, Kelas Desain Grafis, Kelas Teknik Komputer dan Jaringan, Kelas Aplikasi Perkantoran, Kelas Otomotif ,Kelas Kelistrikan dan Kelas Rekayasa Perangkat Lunak

Revolusi Industri kini tengah memasuki babak baru yakni revolusi Industri 4.0 dimana Industri ini merupakan proses produksi di seluruh dunia yang mengombinasikan tiga unsur penting, yakni manusia, mesin/robot, dan big data (Prasetyo dan Sutopo, 2018). Kombinasi tiga unsur itu akan menggerakkan seluruh produksi menjadi lebih efisien serta lebih cepat dan masif. Sesuai dengan tujuan Revolusi Industri 4.0 yang dicetuskan oleh Profesor Klaus Schwab, seorang ekonom Jerman dan pendiri World Economic Forum, bahwa dunia akan difokuskan pada peningkatan produksi dengan memanfaatkan teknologi terkini dan mengganti penggunakan sumber daya yang berasal dari manusia dengan alat (teknologi). Karena, kemajuan teknologi semakin cepat maka manusia seharusnya mampu beradaptasi lebih cepat. Melihat bahwa peran teknologi sudah menutupi apa yang sebelumnya dikerjakan oleh tenaga kerja manusia.

Adaptasi yang perlu dilakukan adalah meningkatkan daya saing dan kualitas tenaga kerja dalam negeri agar dapat menyesuaikan dengan perubahan di pasar kerja (Teuku, Ivan dan Affabile, 2018). Disisi lain, terdapat permasalahan yang cukup serius di dunia kerja kita. Angkatan kerja yang diharapkan dapat siap memasuki dunia kerja ternyata banyak yang belum sipa memasuki dunia kerja. Hal ini yang mengakibatkan semakin meningkatnya tingkat pengangguran di Indonesia. Data menunjukan bahwa pengangguran tertinggi di Indonesia adalah lulusan SMK yaitu sebesar 11,24\% (BPS, 2018). Oleh karena itu, salah satu cara dalam menghadapi Revolusi Industri 4.0 ini adalah adanya kesadaran setiap angkatan kerja khususnya para pelajar untuk berusaha menguasai keahlian atau skill untuk melahirkan tenaga kerja profesional ataupun jenis usaha yang sangat diperlukan guna mendapatkan keseimbangan dengan keberadaan teknologi sekarang.

Bagi yang sudah memiliki keahlian tetap harus berusaha meningkatkan keahliannya dan yang sudah memiliki keahlian tetapi tidak relevan maka harus segera merubahnya sesuai dengan kebutuhan pasar sekarang. Dalam menumbuhkan kesadaran-kesadaran tersebut dalam lingkungan sosial tentu diperlukan upaya-upaya yang dapat mendorong lingkungan pada kondisi kesadaran akan keahlian tersebut. Upaya yang dapat dilakukan untuk meningkatkan kesadaran terhadap lingkungan yaitu melalui media informasi yang sangat banyak tersebar dewasa ini dan mudah diakses oleh siapapun. Media promosi adalah sarana mengomunikasikan suatu produk atau jasa atau brand atau 


\section{JURNAL ABDIMAS

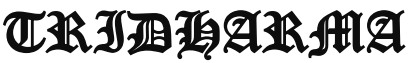

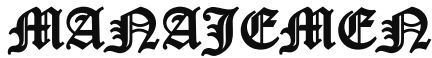

P-ISSN 2715-7105, E-ISSN 2716-070X

Jurnal ABDIMAS Vol. 1,No.2, Mei 2020, Hal (75-83)

@Prodi Manajemen Fakultas Ekonomi Universitas Pamulang

Email: abdimasjurnal.unpam@ gmail.com Telp: (021) 741-2566 perusahaan dan lainnya agar dapat dikenal masyarakat lebih luas. (Daniel, 2012).

Media promosi yang paling tua adalah dari mulut ke mulut, dilanjutkan dengan media promosi konvensional berupa: brosur, poster, spanduk, billboard, banner, flyer, reklame, iklan $\mathrm{TV}$, radio, media cetak (koran/ majalah) dan sebagainya. Media promosi tersebut berkembang dengan maraknya promosi ranah digital seperti promosi melalui jejaring sosial di Facebook dan Twitter. Namun, tidak satu pun media yang benar-benar dikategorikan mutlak dari segi ketepatan dan efektivitas. Masing-masing memiliki kelebihan dan kekurangan.

Berdasarkan uraian diatas, dapat kita lihat bahwa kesadaran pemuda (angkatan kerja) dan pelajar dalam menyadari pentingnya meningkatkan kualitas diri agar dapat meningkatkan daya saing tenaga kerja di Indonesia sangat diperlukan. Pemuda sangat dituntut beradaptasi dengan cepat dalam mengahapi perubahan yang terjadi dalam era Revolusi Industri 4.0 ini, maka penting untuk menguasai serta meningkatkan keahlian skill. Karena Pemuda memiliki peran penting dalam menghadapi Revolusi Industri 4.0, maka dilakukan kegiatan yang mencoba sesuatu yang dapat memicu kesadaran tersebut serta pentingnya peran media promosi dalam perkembangan ilmu pengetahuan dengan Pengabdian Kepada Masyarakat (PKM) yang dilakukan oleh dosen Program Studi Teknik Industri-Unpam dengan judul: Mempersiapkan Generasi Muda yang Kreatif dan Inovatif dalam Menghadapi Industri 4.0 di Rumah Gemilang Indonesia" dengan cara memberikan pemahaman dan mensosialisasikan pemanfaatan media promosi dalam mengahadapi era revolusi industri 4.0 menggunakan prinsip-prinsip sederhana yang sering ditemui dalam kehidupan sehari-hari kepada peserta pelatihan di Rumah Gemilang Indonesia (RGI).

PKM ini tidak hanya sekali saja dilakukan semoga kedepan dapat menjalin kerja sama kembali dengan Rumah Gemilang Indonesia untuk kegiatan lain yang membawa manfaat bagi peserta didik yang berlatar belakang anak-anak yatim, piatu serta kaum duafa. Kegiatan yang akan dilakukan kedepan bisa beriringan dengan visi misi yayasan.

\section{RUMUSAN MASALAH}

Dari identifikasi masalah tersebut, dapat dirumuskan masalah sebagai berikut:

1. Apakah siswa Rumah Gemilang Indonesia Sudah memahami tentang konsepera revolusi industry 4.0 ?

2. Apakah peserta didik siap bersaing dalam era revolusi industry melalui media promosi ?

Apakah pelatihan tentang minat dan bakat peserta didik terkait media promosi sosialmedia?

\section{TUJUAN PELAKSANAAN}

Tujuan umum dari kegiatan Pengabdian Kepada Masyarakat ini adalah membantu peseta pelatihan Rumah Gemilang Indonesia (RGI) dalam mengatasi masalah menghadapi era revolusi industri 4.0 dalam bentuk pemanfaatan media sosial sebgai media promosi.

Secara khusus tujuan kegiatan Pengabdian Kepada Masyarakat ini adalah:

1. Memberikan pemahaman mengenai era revolusi industri 4.0 kepada peserta pelatiahan di Rumah Gemilang Indonesia (RGI) .

2. Mempersiapkan peserta didik agar dapat siap bersaing dalam era revolusi industri melalui media promosi dan lebih dapat memanfaatkan media sosail sebagai saran untuk berkrativitas dan inovasi.

Menjadi sarana Pengabdian Kepada Masyarakat melalui pengembangan minat dan bakat peserta pelatihan di Rumah Gemilang Indonesia (RGI).

\section{TINJAUAN PUSTAKA}

\section{RumahGemilang Indonesia}

Rumah Gemilang Indonesia (RGI), berdiri di lahan wakaf seluas $2.300 \mathrm{~m} 2$ yang bertempat di Kampung Kebon Kopi, 


\section{JURNAL ABDIMAS

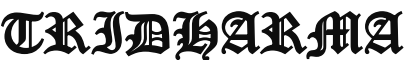

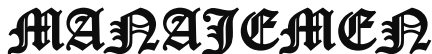

P-ISSN 2715-7105, E-ISSN 2716-070X

Jurnal ABDIMAS Vol. 1,No.2, Mei 2020, Hal (75-83)

@ Prodi Manajemen Fakultas Ekonomi Universitas Pamulang

Email: abdimasjurnal.unpam@gmail.com Telp: (021) 741-2566
Kelurahan Pengasinan, Kecamatan Sawangan, Kota Depok Jawa Barat.

Rumah Gemilang Indonesia saat ini membuka delapan jurusan, yaitu:

a. Kelas Tata Busana

Disini siswa akan belajar keterampilan mengenai dunia fashion merancang sebuah pola dan mengoprasikan mesin jahit.

b. Kelas Fotografi dan Videografi

Disini siswa akan belajar keterampilan mengenai editing foto dan video. Pengambilan foto dan video secara benar dan profesional.

c. Kelas Desain Grafis

Disini siswa akan belajar keterampilan mengenai bagaimana menjadi seorang desainer handal.

d. Kelas Teknik Komputer dan Jaringan Disini siswa akan belajar keterampilan mengenai dunia IT seperti jaringan, web, mikrotik, hadware dan software.

e. Kelas Aplikasi Perkantoran

Disini siswa akan belajar keterampilan mengenai beberapa aplikasi yang ada di perkantoran seperti akun sosial media dan Microsoft Office.

f. Kelas Otomotif

Disini siswa akan belajar keterampilan mengenai dunia mekanik dan perbengkelan seperti belajar kerja mesin, kelistrikan, service dan manajemen bengkel.

g. Kelas Kelistrikan.

Disini siswa akan belajar keterampilan instalasi listrik rumah tangga, pemanfaatan tenaga listrik, pemasangan dan pengoperasian system distribusi.

h. Kelas Rekayasa Perangkat Lunak

Disini siswa akan belajar keterampilan mebuat web, game dan bahasa pemograman html, java script dan style sheet.

\section{RevolusiIndustri 4.0}

Revolusi industri telah terjadi sejak tahun 1750-an dan terus berlanjut sampai sekarang. Dimulai dari mesin uap yang mendominasi industri saat itu, dari kereta sampai mesin penggerak turbin. sekarang memasuki revolusi industri ke 4, semuanya telah berubah secara dramatis. Tren otomatisasi, pertukaran data terkini, komputasi awan, Internet of things (IoT), kecerdasan buatan atau artificial intelligence (AI) dan semua hal virtual yang mampu memudahkan kegiatan operasional kita. Hampir semua hal.

Ada empat prinsip rancangan dalam Revolusi Industri 4.0. Prinsip-prinsip ini membantu perusahaan mengidentifikasi dan mengimplementasikan skenarioskenario dalam revolusi Industri 4.0

1. Interoperabilitas (kesesuaian): Kemampuan mesin, perangkat, sensor, dan manusia untuk berhubungan dan berkomunikasi dengan satu sama lain lewat Internet of Things (IoT) atau Internet of People (IoP). IoT akan mengotomatisasikan proses ini secara besar-besaran

2. Transparansi informasi: Kemampuan sistem informasi untuk menciptakan salinan dunia fisik secara virtual dengan memperkaya model pabrik digital dengan data sensor. Prinsip ini membutuhkan pengumpulan data sensor mentah agar menghasilkan informasi konteks bernilai tinggi.

3. Bantuan teknis: Pertama, kemampuan sistem bantuan untuk membantu manusia dengan mengumpulkan dan membuat visualisasi informasi secara menyeluruh agar bisa membuat keputusan bijak dan menyelesaikan masalah genting yang mendadak. Kedua, kemampuan sistem siber-fisik untuk membantu manusia secara fisik dengan melakukan serangkaian tugas yang tidak menyenangkan, terlalu berat, atau tidak aman bagi manusia.

Keputusan mandiri: Kemampuan sistem siber-fisik untuk membuat keputusan sendiri dan melakukan tugas semandiri mungkin. Bila terjadi pengecualian, gangguan, atau ada tujuan yang 


\section{JURNAL ABDIMAS

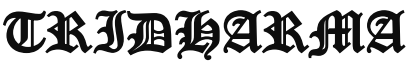

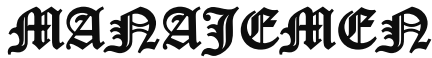

P-ISSN 2715-7105, E-ISSN 2716-070X

Jurnal ABDIMAS Vol. 1,No.2, Mei 2020, Hal (75-83)

@Prodi Manajemen Fakultas Ekonomi Universitas Pamulang

Email: abdimasjurnal.unpam@gmail.com Telp: (021) 741-2566 berseberangan, tugas didelegasikan ke atasan.

\section{Kreatif, Inovatif, Kesuksesan}

Kreativitas merupakan kemampuan mengembangkan ide dan cara-cara baru dalam memecahkan masalah dan menemukan peluang dan ide untuk menciptakan sesuatu yang baru \& berbeda, atau istilah lain "Thinking New Things". Kreativitas menurut Munandar dalam Sunaryo (2002), adalah kemampuan untuk mengkombinasikan, memecahkan atau menjawab masalah, dan cerminan kemampuan operasional anak kreatif.

Inovasi merupakan kemampuan menerapkan kreatifitas dalam rangka memecahkan masalah dan menemukan peluang, atau suatu gagasan \& ide-ide yang berguna dan dapat dijual, atau dalam istilah lain yaitu "Doing New Things". Sedangkan menurut UU Nomor 19 Tahun 2002, inovasi adalah kegiatan penelitian, pengembangan, dan atau pun perekayasaan yang dilakukan dengan tujuan melakukan pengembangan penerapan praktis nilai dan konteks ilmu pengetahuan dan teknologi yang sudah ada ke dalam produk atau pun proses produksinya.

Definisi sukses adalah berhasil, beruntung. Yaitu tercapainya suatu tujuan, harapan dan mimpi. Sukses adalah mendapatkan apa yang diinginkan. Kebahagiaan adalah menginginkan apa yang didapatkan. Kreatif memiliki daya cipta atau berdaya cipta, sementara inovatif berdaya perubahan atau pembaruan. Kreatif menciptakan sesuatu yang berbeda, sementara inovatif menciptakan sesuatu yang belum ada.

Untuk mengembangkan cara berfikir kreatif dan inovatif, dapat dilakukan dengan cara : memiliki mimpi \& imajinasi, melatih diri untuk berfikir berbeda (out of the box) dari yang lain, mendengarkan orang lain dan terus belajar serta berlatih.

\section{METODE PELAKSANAAN}

Metode pelaksanaan yang akan digunakan dalam kegiatan Pengabdian Kepada Masyarakat di Rumah Gemilang Indonesia untuk mewujudkan tujuan dari PKM yaitu melalui penyuluhan interaktif yang didalanya terdapat berbagai aktivitas:

\section{Persiapan}

Adapun tahap-tahap yang dilakukan dalam kegiatan ini meliputi:

a. Surveiawal Pada tahap ini dilakukan survei ke lokasi RumahGemilang Indonesia, Depok.

b. FiksasiJadwal

Pada tahap ini dilakukan penentuan waktu kegiatan.

c. Persiapan Materi Kegiatan

Pada tahap ini dilakukan penyusunan bahan/materi kegiatan yang meliputi: slide powerpoint dan handout.

Materi pertama yaitu mengenai era revolusi industri 4.0 dengan narasumber Ibu Laily M. Zubaedah., S.T., MBA., CT., CMA dimana materi ini berisikan mengenai pengenalan terhadap revolusi industri 4.0, pemahaman revolusi industri 4.0, pemahaman tentang disurpsi "harus berkompetisi, untuk bisa menang (for you to win, you've go to make somebody lose)" ala Michael Porter, pembahasan mengenai dampak revolusi industry 4.0, perubahan yang akan ada ada saat era revolusi industri 4.0, dan kompetensi apa yang dibutuhkan pada saat revolusi industri 4.0. Pemaparan materi diberikan salam satu jam dimana setalah pemaparan materi selsai akan dilakukan sesi tanya jawab.

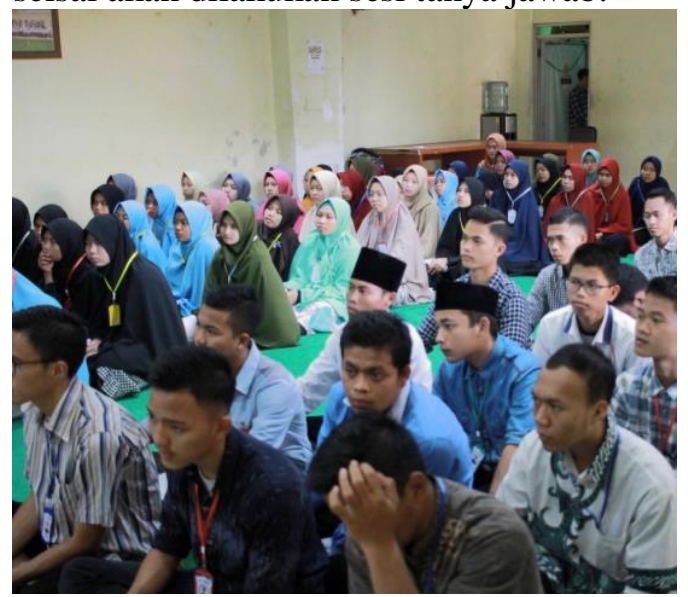




\section{JURNAL ABDIMAS

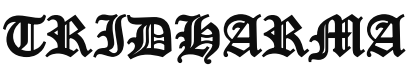

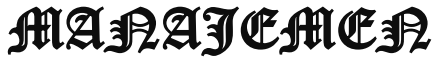

P-ISSN 2715-7105, E-ISSN 2716-070X

Jurnal ABDIMAS Vol. 1,No.2, Mei 2020, Hal (75-83)

@ Prodi Manajemen Fakultas Ekonomi Universitas Pamulang

Email: abdimasjurnal.unpam@gmail.com Telp: (021) 741-2566
Gambar 1.Peserta focus mendengarkan arahan dari pemateri

Sesi Tanya jawab dibagi menjadi 2 sesi yaitu terdiri sesi hanya tiga pertanyaan dan sesi kedua hanya 3 pertanyan. Sesi Tanya jawab ini dilaksankan untuk

Memancing keaktifan para peserta didik yang mengikuti kegiatan ini. Selain itu setiap peserta didik dalam kegiatan penyuluhan ini mendapatkan materi.

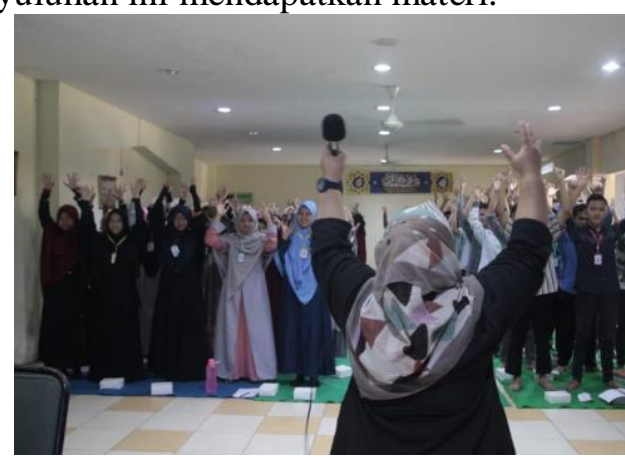

Gambar2.Pesertamengikutiarahanpe mataeri

Materi pertama dibagikan pada saat sebelum narasumbe rpertama memulai pemaparan materi. Tujuannya agar para peserta dapat mengikut imateri yang di paparkan oleh narasumber. Selain pemaparan materidiputarkan juga beberapa video yang berhubungandengan era revolusi industri 4.0. Seperti video sebuah pabrik yang awalnya menggunakan tenaga kerja manusia sekarang digantikan semuanya oleh tenaga mesin, video pelayanan di SPBU yang sudah menggunakan mesin otomatis sebagai pengganti tenaga manusia, begitu pula pada video pintu tol dimana fungsi petugas tol digantikan oleh mesin otomatis. Setelah medengar pemapara nmater iini diharapkan dapat mengedukasi peserta didik mengenai pemahaman terhadap konsep Revolusi Industri 4.0 yang tengah berkembang. Setelah pemahaman diwujudkan, peserta didik diorientasikan untuk dapat mengidentifikasi kemampuan, baik soft skill maupun hard skill yang dibutuhkan di era revolusi industri 4.0. Pemahaman oleh peserta didik terhadap konsep dan kemampuan mengidentifikasi hal-hal yang dibutuhkan di era RevolusiIndustri 4.0 akan berimplikasi pada kesiapan sumberdaya manusia yang terampil dan inovatif dalam dunia tenaga kerja.

\section{Pemateri 2}

Materi kedua yaitu mengenai media promosi dengan narasumber Bapak Ade Irawan S.T., M.M. pada materi kedua membahas mengenai pemanfaatan media sosial sebagai media promosi. Di awali dengan pengertian media sosial, pengertian promosi, tujuan promosi, advertising, jenis kegiatan promosi, pesan dalam promosi. Pemaparan materi diberikan salam satu jam dimana setalah pemaparan materi selsai akan dilakukan sesi tanya jawab. Sesi tanya jawab dibagi menjadi 2 sesi yaitu terdiri sesi hanya tiga pertanyaan dan sesi kedua hanya 3 pertanyan. Sesi tanya jawab ini dilaksankan untuk memancing keaktifan para peserta didik yang mengikuti kegiatan ini. Selain itu setiap peserta didik dalam kegiatan penyuluhan ini mendapatkan materi.

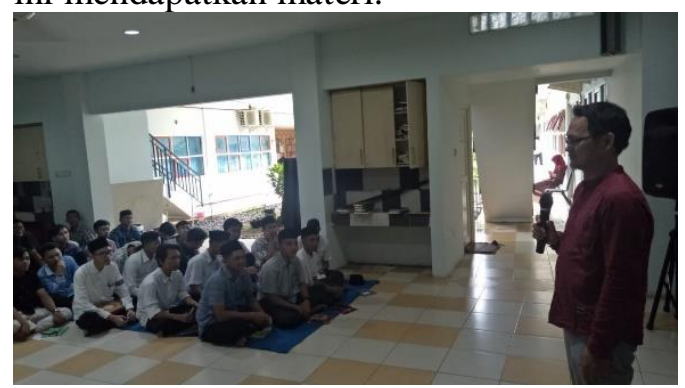

Gambar 3. PemaparanMateri oleh Ade Irawan

Materi pertama dibagikan pada saat sebelum narasumber pertama memulai pemaparan materi. Tujuannya agar para peserta dapat mengikuti materi yang di paparkan oleh narasumber. Pada materi ini akan di paparkan pula tenatng perkembangan media promosi yang mulai maraknya promosi ranah digital seperti promosi melalui jejaring sosial di Facebook dan Twitter. Namun, tidak satu 


\section{JURNAL ABDIMAS

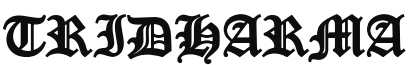

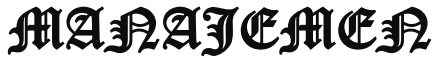

P-ISSN 2715-7105, E-ISSN 2716-070X

Jurnal ABDIMAS Vol. 1,No.2, Mei 2020, Hal (75-83)

@Prodi Manajemen Fakultas Ekonomi Universitas Pamulang

Email: abdimasjurnal.unpam@gmail.com Telp: (021) 741-2566 pun media yang benar-benar dikategorikan mutlak dari segi ketepatan dan efektivitas. Masing-masing memiliki kelebihan dan kekurangan. Maka, dalam memanfaatkan media promosi secara maksimal, dibutuhkan kemampuan menciptakan kreasi baru dan unik agar pesan-pesan dapat melekat pada konsumen, sehingga tujuan menjangkau lebih banyak konsumen dan memaksimalkan profit perusahaan dapat tercapai. Selain itu pada pamaparan materi mengani media promosi diberikan pula beberapa contoh pemanfaatna media promosi, seperti: Sensory Branding, Ambient Art, dan Flash Mob. Sensory Branding yang melibatkan panca-indera manusia seperti mata-penglihatan, hidungpenciuman, telinga-pendengaran, kulitperasa, dan mulut-pengecap untuk memancing persepsi konsumen terhadap suatu produk/brand tertentu. Misalnya: Roti Boy, saat kita melewati gerainya, tercium lah aroma yang enak dan khas membuat kita membayangkan bentuk dan rasa dari Roti Boy tersebut tanpa harus melihat gerai itu sendiri. Contoh lain adalah alunan musik penjual es krim dengan lagu khas dari Walls. Ambient Art adalah penyajian informasi dengan teknik artistik yang juga mengandung pesan tersembunyi, di mana paparan dari waktu ke waktu memungkinkan pengunjung untuk memahami sesuatu tentang sumbersumber informasi yang mewakili. Contohnya adalah gambar kentang McDonalds yang dilukis di jalanan aspal yang dilalui banyak orang, tetapi ukiran kentang yang berbentuk garis lurus itu dijadikan zebra cross. Penggunaan seni ambient art ini memancing orangorang yang melewati zebra cross itu memikirkan McDonalds. Flash Mob dapat diartikan sebagai sekelompok orang yang berkumpul pada waktu dan tempat yang telah ditetapkan untuk melakukan suatu hal bersamaan secara spontan. Massa Flash Mob diatur melalui komunitas online, web blog, news group, email surat berantai, pesan singkat, ataupun telepon. Pesan lalu diteruskan beberapa kali untuk meningkatkan banyaknya massa. Misalnya, ada event di 2011 kemarin bertema: Sumpah Pemuda Flash Mob, yang diadakan di Central Park. Pesan singkat yang disebarkan via email berisi instruksi singkat untuk mengikuti event. Setelah medengar pemaparan materi ini diharapkan dapat memacing pesrta didik agar dapat memnafaatkan media sosial sebagai peluang usaha. Maksudnya tidak hanya terpaku dengan mencari kerja melaikan bisa kita manfaatkan untuk membuka lapangan kerja. Kegiatan penyuluhan ini diharapkan mampu memberikan dampak jangka panjang, melalui pelatihan terhadap pemuda, karena pemuda memiliki peran sebagai agent of change atau pemuda adalah pilar penggerak yang diharapkan mampu menjadi penerus penggerak kemajuan bangsa. Tetapi dengan derasnya arus persaingan global dan regional, tantangan yang dihadapi oleh pemuda pun semakin beragam. Oleh karena itu kesadaran dan kesiapan pemuda harus segera diinisasi sejak dini. PKM ini dilakukan dengan menjalankan kegiatan penyuluhan di Rumah Gemilang Indonesia yang bertujuan untuk membantu masyarakat dalam meningkatkan taraf pengetahuan dan keterampilan sehingga diharapkan dapat meningkatkan kesejahteraannya. Kegiatan ini dibagi menjadi empat tahap kegiatan, yaitu pembekalan, pelaksaaan kegiatan di lokasi, penyusunan laporan, dan evaluasi.

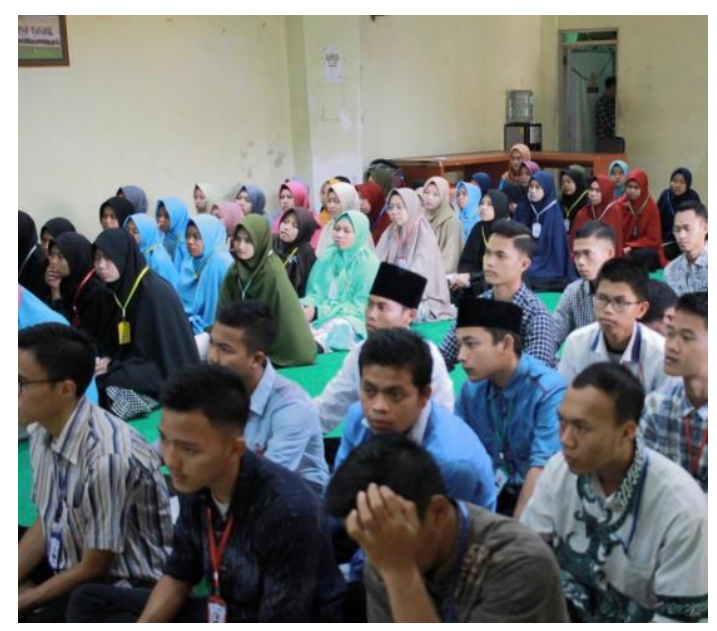




\section{JURNAL ABDIMAS

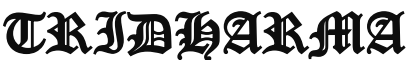

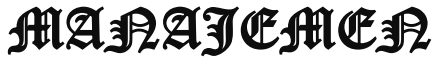

P-ISSN 2715-7105, E-ISSN 2716-070X

Jurnal ABDIMAS Vol. 1,No.2, Mei 2020, Hal (75-83)

@Prodi Manajemen Fakultas Ekonomi Universitas Pamulang

Email: abdimasjurnal.unpam@gmail.com Telp: (021) 741-2566

\section{HASIL DAN PEMBAHASAN}

Pengabdian Masyarakat (LPPM) Universitas Pamulang yang dilakukan oleh dosen-dosen program studi Teknik Industri telah berjalan dengan lancar dan mendapat sambutan hangat dari tempat pelaksanaan kegiatan ini yaitu RumahGemilang Indonesia (RGI), Depok.

Harapan kami dengan pengabdian ini dapat membuka wawasan para santri Rumah Gemilang Indonesia diantaranya bertambahnya keilmuan bagi para santri tentang kreativitas dan inovasi yang dibutuhkan untuk menghadapi persaingan di dunia kerja pada era Industri 4.0.Generasi muda yang mumpuni mampu mempersiapkan mental, spiritual maupun keilmuan sebelum terjun langsung pada era industri 4.0.

Ilmu yang diperoleh pada Pengabdian Masyarakat kali ini diharapkan mampu memberikan semangat baru bagi kita dalam menyampaikan materi dan motivasi serta berkontribusi bagi generasi muda, baik dilingkungan sekolah, kampus dan keluarga.

\section{KESIMPULAN DAN SARAN}

Pelaksanaan kegiatan Pengabdian Kepada Masyarakat oleh Lembaga Penelitian dan Pengabdian Masyarakat (LPPM) Universitas Pamulang yang dilakukan oleh dosen-dosen Teknik Industri ini berjalan dengan lancer dan mendapat sambutan yang positif dari pihak pengelola Rumah Gemilang Indonesia. Dari kegiatan PKM ini dapat ditarik bebrapa kesimpulan :

1. Kegiatan promosi merupakan salah satu kegiatan yang sangat penting untuk era industry 4.0 sehingga perlu untuk dipelajari lebih dalam.

Siswa di RGI memerlukan ilmu-ilmu dari pihak luar khususnya dosen untuk menambah wawasan ilmu pengetahuan.
Davies, R. (2015). Industry 4.0: Digitalisation for Productivity And Growth.

Khasali, R. (2018). Strawberry Generation. Jakarta: Mizan.

Prasetyo, Hoedi dan Sutopo, Wahyudi.2018.Industri 4.0:

Telaahklasifikasiaspek dan arahperkembanganriset. Jurnal Teknik Insdustri (J@TI). Volume 13.No.1. Halaman 17-18.

Rezasyah, Teuku. Ivan dan Affabile.2018. KesiapanSiswa SMK dalamRevolusiIndustri $\quad 4.0$. JurnalPengabdianKepada Masyarakat. Kumawula, Vol. 1, No.2, Agustus 2018, Hal $114-119$.

Shwab, K. (2016). The Fourth Industrial Revolution. New York: Crown Business.

Zhou, K., Taigang L., \&Lifeng, Z. (2015). Industry 4.0: Towards future industrial opportunities and challenges. In Fuzzy Systems and Knowledge Discovery (FSKD), IEEE 12th International Conference, pp. 2147-2152.

\section{DOKUMENTASIFOTO KEGIATAN}

\section{DAFTAR PUSTAKA}




\section{JURNAL ABDIMAS

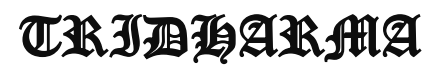

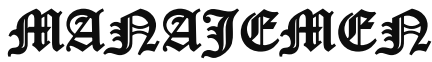

P-ISSN 2715-7105, E-ISSN 2716-070X

Jurnal ABDIMAS Vol. 1,No.2, Mei 2020, Hal (75-83)

@ Prodi Manajemen Fakultas Ekonomi Universitas Pamulang

Email: abdimasjurnal.unpam@gmail.com Telp: (021) 741-2566
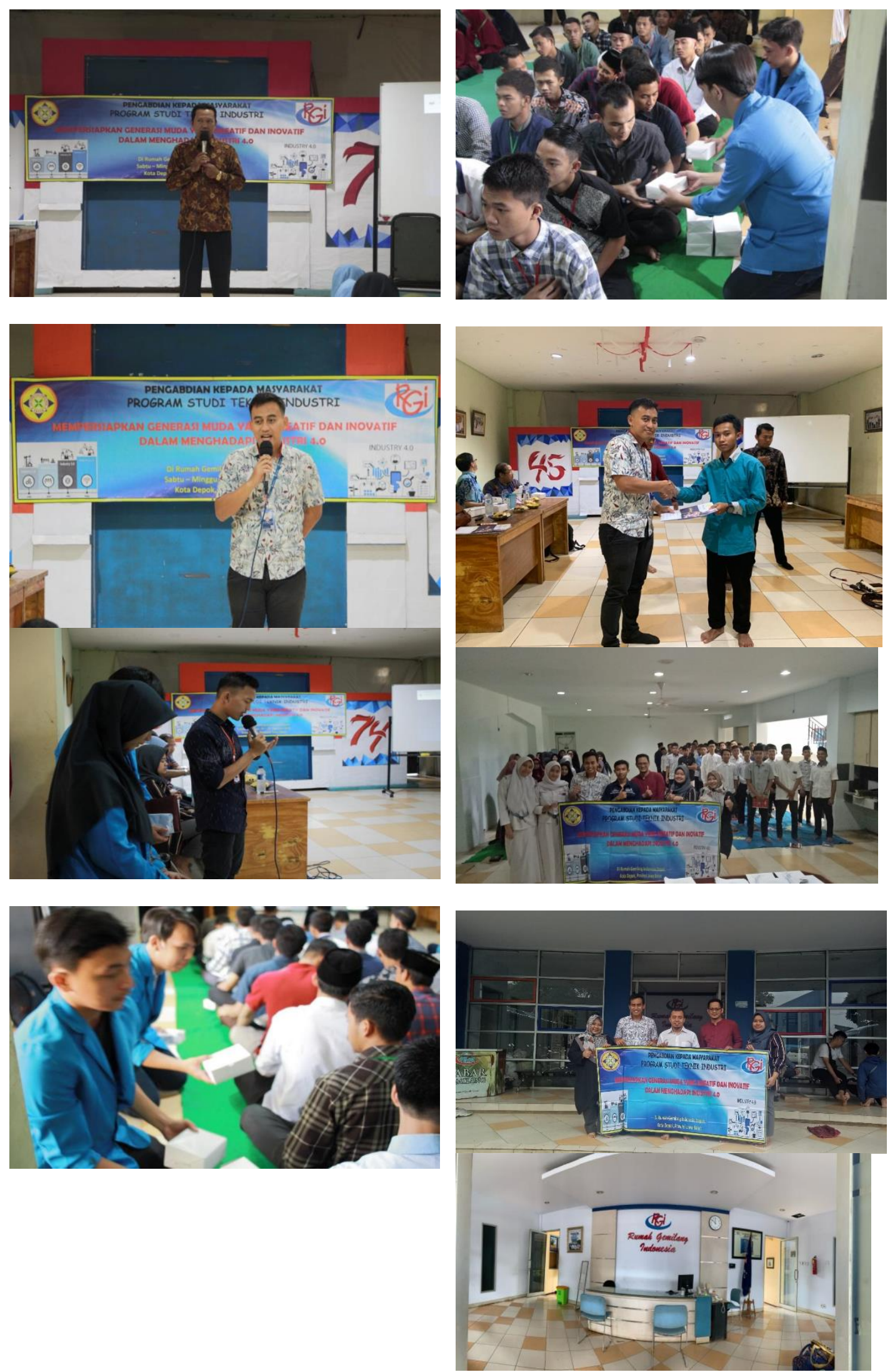
JURNAL ABDIMAS

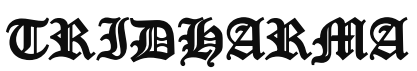

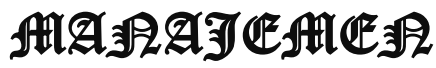

P-ISSN 2715-7105, E-ISSN 2716-070X

Jurnal ABDIMAS Vol. 1,No.2, Mei 2020, Hal (75-83)

@ Prodi Manajemen Fakultas Ekonomi Universitas Pamulang

Email: abdimasjurnal.unpam@ gmail.com Telp: (021) 741-2566
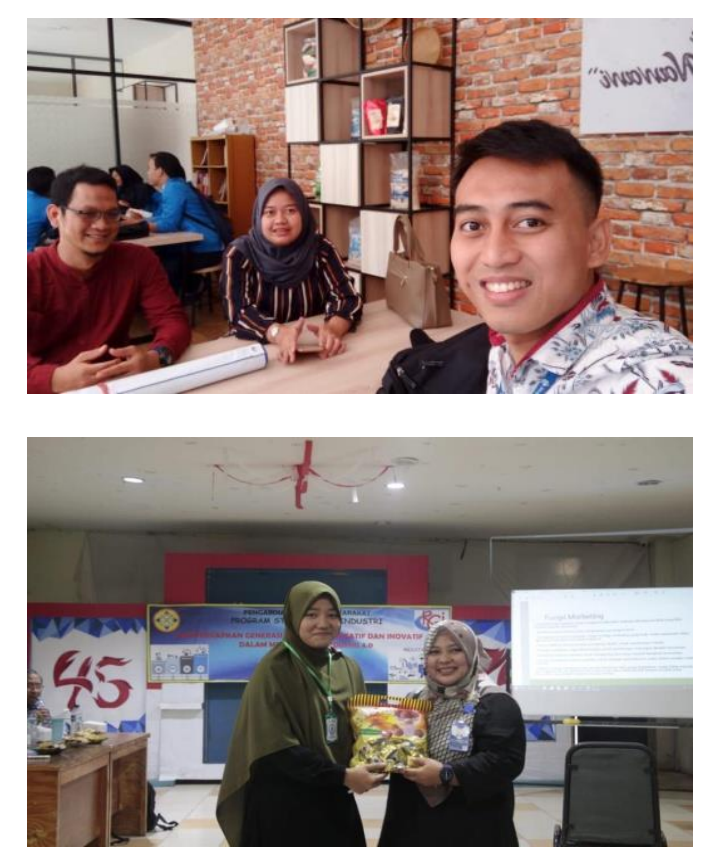